\title{
ANALISANDO STAKEHOLDERS INTERNOS EM UMA INSTITUIÇÃO DE ENSINO SUPERIOR: O CASO NA UNIVERSIDADE FEDERAL DO
} PARÁ

\section{ARTIGO ORIGINAL}

COSTA, Sheila Maria Moreira ${ }^{1}$

MATTOS, Carlos André Corrêa De ${ }^{2}$

COSTA, Sheila Maria Moreira. MATTOS, Carlos André Corrêa De. Analisando stakeholders internos em uma Instituição de Ensino Superior: 0 caso na Universidade Federal do Pará. Revista Científica Multidisciplinar Núcleo do Conhecimento. Ano 05, Ed. 06, Vol. 01, pp. 05-18. Maio de 2020. ISSN: 2448-0959, Link de

acesso: https://www.nucleodoconhecimento.com.br/administracao/analisandostakeholders

\section{RESUMO}

Os gestores de organizações na atualidade não podem ignorar a necessidade de analisar e monitorar os grupos de interesse de que dependem. Esses grupos de interesse são os seus stakeholders. A análise de stakeholders, anteriormente focada no âmbito privado, está cada vez mais presente nas instituições públicas tendo em vista a sua contribuição na agregação de valor por meio da gestão estratégica e no processo de avaliação de desempenho. Este artigo tem como objetivo analisar a presença da Universidade Federal do Pará (UFPA) como uma marca forte na região amazônica na visão de seus stakeholders internos. Para tanto, foi realizada uma pesquisa de caráter qualitativo e quantitativo no campus sede, em Belém, envolvendo

1 Economista. Mestranda no Curso de Direção e Administração de Empresas Faculdad de Ciencias Empresariales.

${ }^{2}$ Administrador. Doutor em Ciências Agrárias. 
docentes, discentes e funcionários técnico-administrativos. Os resultados da pesquisa foram obtidos a partir de entrevistas semiestruturadas, abordando questões acerca da visão que esses indivíduos têm a respeito da universidade em relação à sua presença na sociedade, bem como a eficiência e eficácia de suas ações e competências. Percebeu-se que a UFPA tem uma boa receptividade por parte dos entrevistados, sendo a primeira escolha dos mesmos no que diz respeito à formação e empregabilidade. Os entrevistados destacaram também a relevância que a universidade tem diante da sociedade como uma instituição que promove a ciência e serviços sociais. Assim, é possível concluir que a UFPA contribui para o desempenho regional e é reconhecida por seus stakeholders internos.

Palavras-Chave: Instituições, stakeholders, UFPA.

\section{INTRODUÇÃO}

O ensino superior no Brasil é considerado elemento estratégico para a preparação de um elenco qualificado de profissionais que farão parte do mercado de trabalho, e que tenham reconhecidas habilidades e competências. De acordo com estudos de Jorge, Oliveira e Ferreira (2016, p. 1.475), há, ainda, como parte dessa estratégia de desenvolvimento, um discurso reverberante que visa beneficiar "a inclusão social, por meio de políticas afirmativas, assistência estudantil, democratização do acesso, lei de cotas, dentre outros".

Na leitura de Lourenço e Mano (2014), a massificação e as novas perspectivas sobre o ensino e a globalização "têm pressionado a uma maior abertura da sua atividade à sociedade e a todos os que as rodeiam". Nesse contexto faz-se necessário a identificação e a análise das diferentes partes interessadas como nova exigência administrativa que se traduz como requisito do desempenho organizacional.

As partes interessadas em uma organização foram popularizadas por Freeman (1984) de stakeholders. Esse conceito evoluiu e surgiram definições como a de Bryson (2004), segundo a qual stakeholders são os indivíduos, grupos ou organizações que devem ser levados em consideração pelos líderes, gestores e pessoal da linha da 
frente da organização em questão. Johnson, Scholes e Whittington (2008) definiram stakeholders como os indivíduos ou grupos que dependem da organização para atingir as suas metas e de quem a organização também depende.

Essa abordagem ganhou espaço e se desenvolveu bastante nos anos de 1990 por meio dos trabalhos de Goodpaster (1991), Clarkson (1995), Donaldson e Preston(1995), Mitchell, Agle e Wood (1997), Rowley (1997) e Frooman (1999) entre outros, ficando conhecida como Teoria dos Stakeholders.

No âmbito de instituições de ensino superior, Jongbloed, Enders e Salerno (2008) apresentaram a Teoria de Stakeholders como uma ferramenta de apoio para auxiliar as universidades na classificação e determinação da importância dos seus stakeholders. No momento atual em que está sendo cobrada das universidades uma maior interação com a sociedade (VOLPI, 1996), é relevante a identificação de parceiros e seleção de partes interessadas, visando minorar as implicações advindas de acordos de governança e prestações de contas.

No entendimento de Kettunen (2014), os stakeholders internos de uma instituição de ensino superior são os estudantes e os servidores. Enquanto, de maneira geral, os externos são os parceiros, cujo relacionamento com a instituição geralmente se dá por meio de projetos de pesquisa e desenvolvimento, e os clientes que são os eventuais compradores de algum produto ou serviço que a instituição pode oferecer.

De fato, percebe-se que numa universidade pública, no caso deste estudo, os servidores (docentes e técnico-administrativos), stakeholders internos, são os responsáveis pelo desenvolvimento das políticas de atendimento à sociedade, tanto no ensino como na pesquisa e extensão, além de outros serviços sociais para inclusão como assistência social e jurídica que atendam as demandas da comunidade.

Desta forma, procurou-se analisar a percepção dos stakeholders sobre a Universidade Federal do Pará (UFPA), não só em relação aos aspectos educacionais, enquanto finalidade de seus serviços, mas também nos aspectos sociais que envolvem as ações destinadas aos estudantes e à comunidade em geral, principalmente, as 
políticas de promoção da qualificação profissional dos servidores que respaldam suas ações e suas competências. Sua abrangência, portanto, contempla o contexto acadêmico, social e político no âmbito da sua atuação institucional.

\section{STAKEHOLDERS DE UMA UNIVERSIDADE}

O conceito empresarial de stakeholders foi expandido para as organizações sem fins lucrativos e daí para as organizações públicas. Considerando que muitas Instituições de Ensino Superior (IES) operam de maneira similar a empresas comerciais (CHAPLEO; SIMMS, 2010), a Teoria dos Stakeholders passou a ser utilizada pelos administradores dessas instituições.

Por outro lado, as universidades públicas na atualidade precisam demonstrar a sua relevância para a sociedade (MAINARDES et al., 2010), passando então a atuar mais em projetos de extensão e pesquisa, de forma a atingir determinados setores da sociedade ou até mesmo beneficiar a sociedade como um todo. Para atingir esses objetivos, as universidades públicas começaram a firmar parcerias com o setor externo passando assim a receber em alguns casos recursos e como consequência precisa atingir padrões de eficiência e realizar prestações de contas.

A Teoria dos Sakeholders começou a ser utilizada nas instituições, inicialmente objetivando a identificação dos stakeholders depois as suas demandas e como suprilas. De acordo com Mainardes et al. (2010), "identificar os stakeholders envolvidos com a IES é um passo fundamental no estabelecimento das vantagens competitivas da instituição de ensino, bem como identificar as necessidades destes stakeholders e oferecer meios de supri-las".

As diversas tentativas de classificação de stakeholders feitas no contexto empresarial foram sendo utilizadas ou adaptadas para a situação de instituições públicas. Mainardes et al. (2013) explica que os stakeholders de uma universidade são numerosos e de diversos tipos e existe na literatura diversas tentativas de categorizálos. De maneira geral os estudos destacam como stakeholders de IES a comunidade acadêmica (estudantes, docentes, técnicos, gestores), o governo, agências de 
financiamento, sociedade em geral (histórico dos stakeholders nas IES em MAINARDES et al., 2013).

Dentre as classificações utilizadas com sucesso, será aqui utilizada a de Duderstadt (2000), ampliada posteriormente por Jongbloed; Enders e Salerno (2008) e Matlay (2009), que classifica os stakeholders das IES como: Internos, que abrange os estudantes, docentes, técnicos e gestores; e os Externos, abrangendo os exestudantes, entidades governamentais e profissionais, órgãos de financiamento, fundações, comunidade em geral.

Mais especificamente o presente estudo tem como foco os stakeholders internos, nomeadamente a comunidade acadêmica, considerando que, os estudantes desempenham um papel fundamental no desenvolvimento de uma IES haja vista que o seu sucesso na carreira profissional reflete na IES que estudou (JONGBLOED; ENDERS; SALERNO, 2008); e os funcionários (docentes, gestores e técnicos) representam a força mais importante na manutenção das IES (BOWEN; SHAPIRO, 1998).

No entendimento de Jongbloed, Enders e Salerno (2008) as IES precisam manter um compromisso com os seus stakeholders como forma de entender de que forma estes estão percebendo os serviços prestados e de que maneira esses serviços podem ser melhorados. Este constitui o objetivo do presente estudo.

\section{MATERIAL E MÉTODOS}

\subsection{A PESQUISA}

A análise de stakeholders internos de uma universidade pública será desenvolvida a partir de um estudo de caso. Considera-se o método apropriado uma vez que se pretende estudar o fenômeno no contexto e nos limites da instituição (YIN, 2003). Desse modo a unidade de estudo de caso foi a Universidade Federal do Pará, campus Belém. 
Para o estudo foram selecionadas 200 pessoas que trabalham ou estudam no Campus Belém da UFPA, que representa a sede da Instituição. A amostra buscou a representatividade das principais categorias que transitam no campus universitário de acordo com a seguinte distribuição: 40 gestores, 60 docentes, 60 técnicoadministrativos, 30 alunos concluintes do curso de graduação e 10 de pós-graduação na UFPA em 2017.

Para a seleção dos servidores da UFPA (gestores, docentes e técnicoadministrativos), foi considerado como critério de inclusão o maior envolvimento destes nas suas respectivas categorias funcionais e a maior experiência nas atividades desenvolvidas. Na seleção dos discentes de graduação, o critério de participação no estudo foi estar em fase final de sua graduação, por entender-se que estes teriam uma visão mais ampla sobre a instituição. E, para os discentes de pósgraduação o critério foi o conhecimento sobre pesquisa e produção científica.

A pesquisa realizada foi do tipo quanti-qualitativo, com a coleta de dados feita por meio de entrevistas semiestruturadas com os sujeitos investigados, visto que o estudo de caso se mostra como uma possibilidade de se alcançar não só uma aproximação com aquilo que se deseja conhecer e estudar, mas, também, de adquirir conhecimentos sobre ele e suas relações com o meio, partindo da realidade em que está inserido.

Atendendo a Resolução no 466/12/12 do Conselho Nacional de Saúde sobre Diretrizes e Normas regulamentadoras de pesquisas envolvendo seres humanos, a coleta de dados atendeu os princípios éticos de respeito aos direitos e dignidades das pessoas pesquisadas. Os participantes foram informados do conteúdo da pesquisa e forneceram o consentimento por escrito sendo-Ihes garantido o anonimato durante todo o processo de análise.

Para a análise quantitativa, as respostas dos pesquisados foram inseridas em planilhas de dados no software Excel (programa Office versão 2010). Para as variáveis categóricas utilizou o resumo tabular por meio de frequências absolutas e percentuais, representados por figuras gráficas. 
A análise qualitativa se apresentara em duas dimensões da entrevista (servidores e alunos), serão digitalizas e as informações serão tratadas utilizando-se a técnica de Análise de Conteúdo proposta por Bardin (2011), esse tipo de análise já era utilizada desde as primeiras tentativas da humanidade de interpretar os livros sagrados, tendo sido sistematizada como método apenas na década de 20, por Leavell. Para a qual define um conjunto de procedimentos de análise das comunicações por meio de métodos sistemáticos e objetivos de caracterização do conteúdo das mensagens em três etapas: (1) apresentada como pré-análise (consiste na leitura flutuante de todo o material transcrito); (2) etapa de exploração do material para os registros de categorias iniciais e por última, (3) a etapa definida como inferência e interpretação, onde as categorias iniciais serão agrupadas em categorias temáticas intermediarias e finais.

\subsection{O LÓCUS DA PESQUISA: A UNIVERSIDADE FEDERAL DO PARÁ}

A Universidade Federal do Pará (UFPA), fundada em 1957, é uma das maiores instituições públicas federais de ensino superior e uma das maiores universidades multicampi do Brasil, onde desenvolvem atividades cerca de 60.000 pessoas, entre professores, funcionários técnico-administrativos e alunos, distribuídos em diversos municípios, cuja sede está localizada em Belém, capital do estado do Pará.

A estrutura física da UFPA é composta pelas seguintes unidades e órgãos: 12 campi, 93 polos, 12 institutos, 06 núcleos, 02 hospitais, 01 escola de aplicação, 01 teatro e 01 museu. Ela é considerada a maior universidade da Amazônia tanto em extensão como em contingente de recursos humanos, quantidade de projetos e pesquisas voltadas ao desenvolvimento do ensino superior público. Essa universidade tem sua organização sob a forma de autarquia, estando vinculada ao Ministério da Educação (MEC), cujo princípio fundamental tem por base a integração das três funções: ensino, pesquisa e extensão

O campus sede, em Belém, denominado Cidade Universitária Professor José da Silveira Netto, compõe-se de 05 setores: Básico, Profissional I, Profissional II, Profissional III e Profissional IV, sendo que, fora da área deste campus, localizados 
no centro da capital, estão o Instituto de Ciências da Arte, a Faculdade de Medicina, o Núcleo de Medicina Tropical, o Museu, a Escola de Música, a Escola de Dança e o Teatro e a Escola de Aplicação.

No que se refere aos campi do interior, a UFPA se distribui em uma vasta extensão do estado, com a finalidade de levar educação e formação aos estudantes paraenses em todas as suas regiões. Para isso, a UFPA se faz presente em vários municípios através dos seguintes campi: Abaetetuba, Altamira, Bragança, Capanema, Castanhal, Marajó-Breves, Marajó-Soure, Salinópolis, Tocantins-Cametá e Tucuruí (UFPA, 2015).

Na UFPA existem 76 faculdades de graduação nas várias áreas da ciência e tecnologia e diversos programas de pós-graduação lato sensu (especialização), desenvolvidos pelos institutos. Em relação à pós-graduação stricto sensu, possui vários programas de mestrado e doutorado, vinculados aos institutos, sendo que o mestrado se divide em acadêmico, com 57 cursos, e profissional, com 16, e o doutorado possui 35cursos. Todos esses cursos são aprovados pela Capes e CNPq, com selo de qualidade.

\section{RESULTADOS}

A amostra total foi composta por um total de 200 entrevistados, enquanto sujeitos da pesquisa e considerados os stakeholders internos da UFPA, distribuídos em cinco categorias: gestores (40), docentes (60), técnico-administrativos (60) e discentes (40) concluintes da graduação e pós-graduação conforme distribuição apresentada na Figura 1 
Figura 1. Distribuição da amostra da pesquisa com os servidores da UFPA.

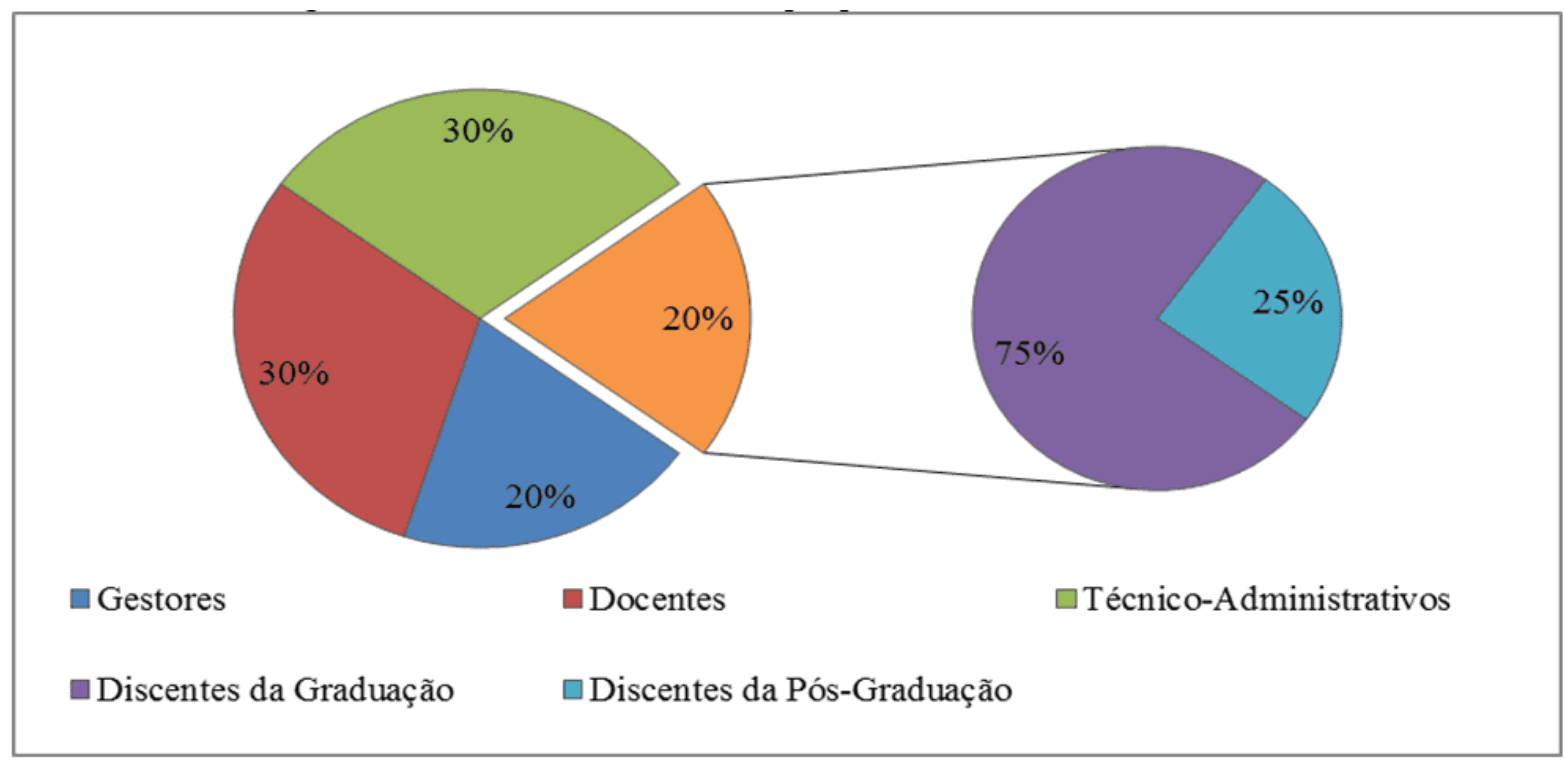

Para a análise dos dados obtidos a partir das entrevistas realizadas com os servidores e alunos foi realizada inicialmente uma análise de conteúdo dos resultados procedendo a sistematização, categorização e análise exploratória.

$\mathrm{Na}$ questão inicial os servidores e estudantes foram indagados se consideravam a UFPA importante no cenário educacional pelo fato de pertencer à esfera federal. Tanto os servidores quanto os estudantes responderam positivamente a essa questão justificando nas suas falas que o apoio da União é importante para que a UFPA continue formando profissionais e produzindo ciência, tecnologia e cultura. Destacase na Figura 2 a opinião de alguns servidores e estudantes onde são ressaltadas as questões de formação qualificada que os discentes recebem, inclusão social, variedade de cursos e o desenvolvimento da pesquisa e da extensão. 
Figura 2. Comentários dos servidores e estudantes sobre a importância de a UFPA pertencer à esfera federal.

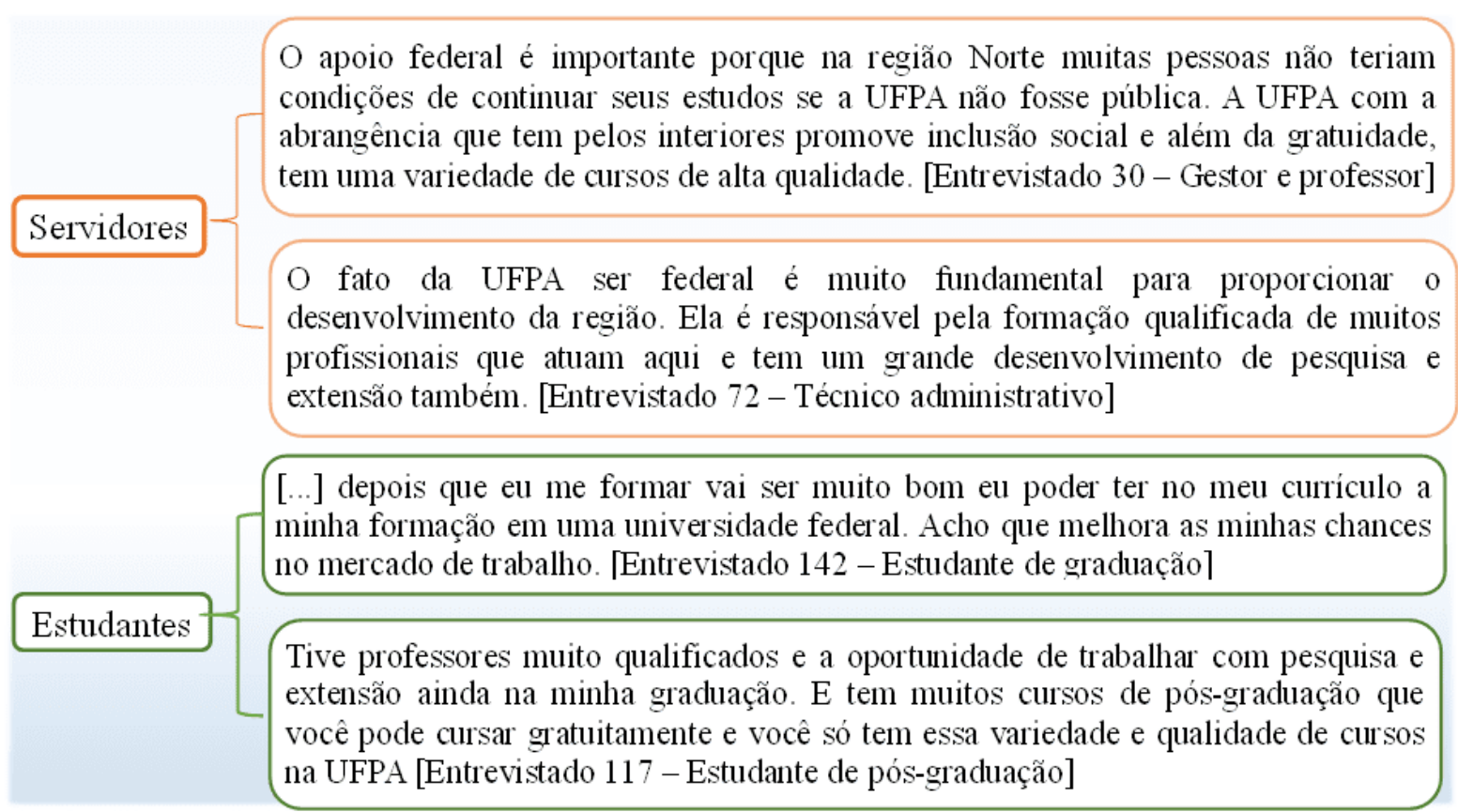

Indagados se os serviços (ensino, pesquisa e extensão) e a produção (científica, tecnológica e cultural) da UFPA demonstram sua competência diante da sociedade, os servidores se manifestaram de maneira positiva: enfatizaram que as ações desenvolvidas pela UFPA são resultantes do trabalho das competências (gestores e colaboradores), e isso vai impactar nos serviços prestados e na produção demonstrando para a sociedade que a UFPA está trabalhando nos três eixos: ensino, pesquisa e extensão.

Os estudantes por sua vez, apesar de concordarem que a UFPA desenvolve atividades nos três eixos, mostrando a sua competência para a sociedade, mostramse preocupados com cortes de verbas, relatando também que muitos discentes não têm oportunidade de participarem de projetos de ensino e extensão. Sobre esse assunto um gestor entrevistado (Entrevistado 65) relatou que o Regulamento de Graduação (Resolução n. 4.399 CONSEPE de 14.05.2013) prevê que os Projetos Pedagógicos dos Cursos da UFPA devem incluir as atividades de pesquisa e/ou extensão como componentes do percurso acadêmico dos cursos de graduação, 
estabelecendo um mínimo de $10 \%$ da carga horária do curso dedicado às atividades de extensão para integralização da graduação. A Figura 3 apresenta alguns comentários de servidores e estudantes.

Figura 3. Comentários dos servidores e estudantes sobre como os serviços (ensino, pesquisa e extensão) e a produção (científica, tecnológica e cultural) da UFPA demonstram sua competência diante da sociedade.

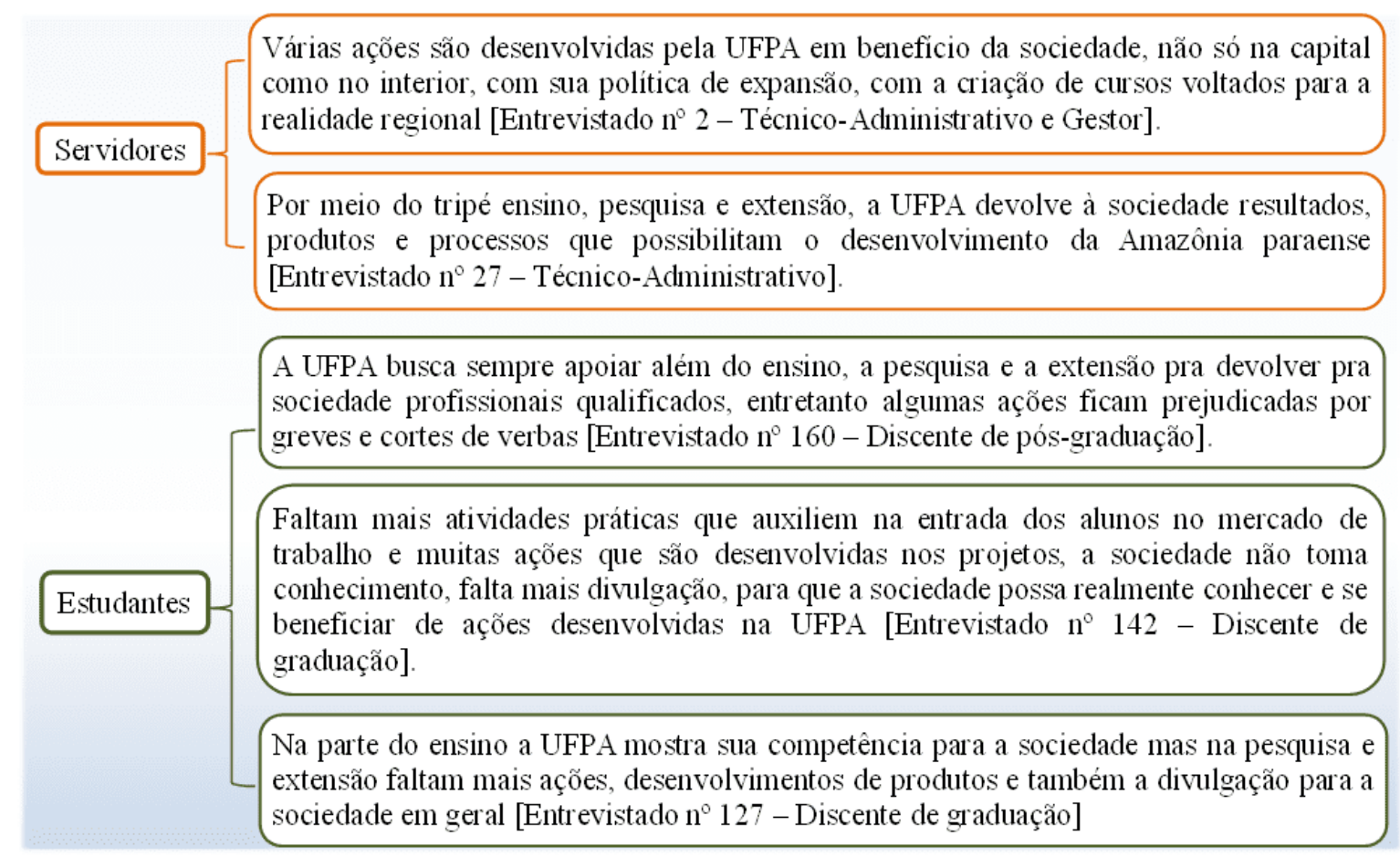

De modo geral, de acordo com a visão dos servidores, tanto os serviços através do ensino de graduação e pós-graduação, como pesquisa com grandes projetos de desenvolvimento da região Amazônica em todas as áreas do conhecimento, e os programas e projetos extensão para o fortalecimento da relação com as comunidades, bem como seu cabedal de produção científica, tecnológica e cultural são evidentes na UFPA, que adota o modelo multicampi de desenvolvimento de suas ações, não podendo mais limitar seu raio de abrangência para o desenvolvimento, demonstrando sua competência nas ações e missão de levar adiante o compromisso de formar o homem e o profissional competentes para atuar na sociedade. 
Nesse sentido, o entendimento dos servidores a esse respeito encontra amparo nas argumentações de Bampi e Diel (2015), que enfatizam o modelo multicampi de universidade como aquele que mantém, atualmente, melhores relações com a sociedade, visto que abarca todo o contexto de sua abrangência para levar conhecimento e desenvolvimento através de suas competências para formar novos profissionais mais competentes e envolvidos com as problemáticas políticas e sociais. É o caso da UFPA, que objetiva alcançar as pessoas nos mais longínquos espaços da Amazônia, em suas próprias comunidades e com elas discutir e construir novos conhecimentos e saberes.

Ressalta-se, entretanto que a visão dos estudantes tende a ser um pouco mais crítica considerando que estes são os stakeholders centrais das IES e receptores do conhecimento, são os mais sensíveis aos problemas que a instituição possa apresentar uma vez que isso vai impactar diretamente na sua formação.

$\mathrm{Na}$ tentativa de entender um pouco mais sobre os estudantes, foi inquirido a estes $\mathrm{O}$ que o levou a escolher a UFPA para realizar seus estudos. A questão pode ter múltiplas respostas e a Figura 4 apresenta os resultados.

Figura 4. Motivo de escolher a UFPA para estudar

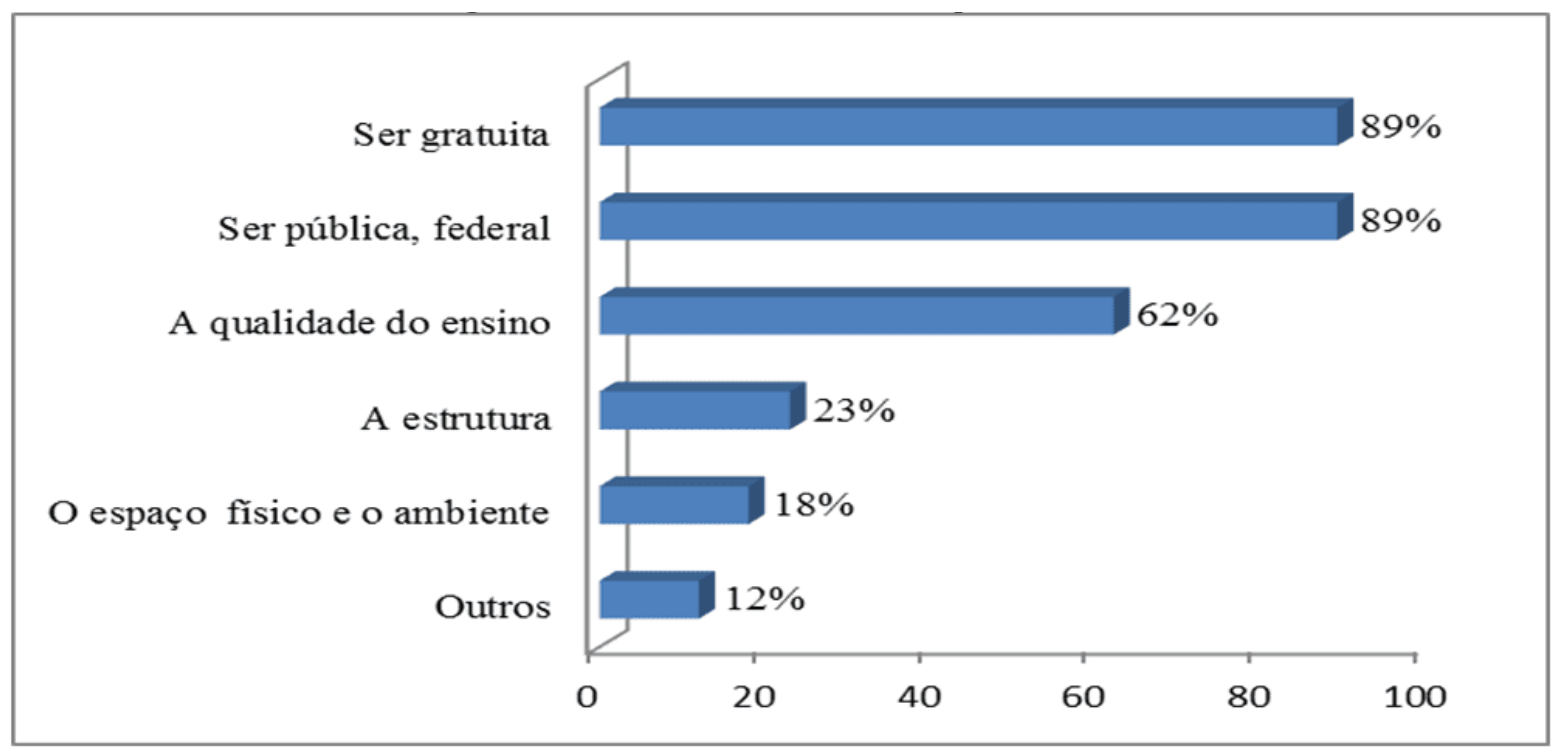


Ser pública federal e ser gratuita foram as categorias de maior preferência dos estudantes, por ser uma universidade tradicional no ensino superior, o que estimula muito mais os jovens paraenses, especialmente os de classes média e baixa que veem na UFPA a oportunidade de cursar uma faculdade e o apoio que recebem da instituição e de acordo com a grande maioria destes a gratuidade é ponto relevante, não atentando para a qualidade do ensino. Por outro lado, oferecer qualidade de ensino foi a escolha de $62 \%$ dos estudantes, porque, segundo eles, a federalidade da universidade dá maior suporte aos universitários, como justificou um entrevistado:

A UFPA prepara qualitativamente os estudantes para o mercado como profissionais competentes, além de ser uma instituição pública de ensino superior reconhecida nacional e internacionalmente o que também qualifica e credencia os egressos que dela provêm a ocupar cargos na sociedade. No meu caso, eu fiz aqui a graduação na área de biológica, estou concluído o mestrado na mesma área, já atuo na profissão e me sinto competente na função que exerço. Acredito que, mesmo havendo algumas dificuldades, justamente por ser uma universidade pública com carência de recursos, é o aluno que deve correr atrás. A UFPA tem bons laboratórios, um grande acervo bibliográfico e, acima de tudo, possui excelentes professores ao nível de doutoramento que contemplam os alunos com muitos conhecimentos e técnicas necessárias à profissão (Entrevistado oํ 165 - Discente de pós-graduação).

A situação da UFPA não é diferente de outras IFES em âmbito global. São diversos os problemas e desafios que as instituições precisam enfrentar no ensino superior (BENEKE, 2011, p. 37). Kotecha (2003) já afirmava que a raiz desses problemas se encontra nas origens de algumas universidades, que se estabeleceram como instituições conservadoras, por natureza, demorando pra se adaptar a mudanças. No entanto, quando a instituição consegue despertar o interesse do seu público-alvo (stakeholders internos), ela consegue liderança e destaque (GUPTA; SINGH, 2010). 


\section{CONCLUSÕES}

A UFPA, dentro do seu programa de redimensionamento e apoio aos servidores e de incentivo à qualificação destes, promove mais incentivo aos que ainda necessitam de melhor formação e comportamento organizacional, para formação de uma consciência e responsabilidade estimulada pela inteligência emocional que promove boas relações interpessoais, cuja ausência ou carência prejudica a imagem que esta instituição tem procurado construir e apresentar aos seus stakeholders.

Entender e priorizar seus stakeholders internos é de suma importância para as IES. Pois é a partir do conhecimento do seu público interno que as IES podem estabelecer se o ensino, a pesquisa e a extensão estão realmente atendendo as demandas de seus stakeholders, se as metas previstas estão sendo cumpridas e se os problemas institucionais estão sendo resolvidos de maneira adequada na visão destes.

A importância dos stakeholders para as IES aumenta quando se leva em consideração os orçamentos que estão sendo constantemente reduzidos ou cortados necessitando a criação de estratégias para a captação de recursos externos para o atendimento. $E$ para apresentar o perfil adequado a ser visto pelos stakeholders externos, nada melhor do que fazer um bom trabalho com os stakeholders internos, pois estes servirão de referência e parte deles futuramente entrarão na rede de stakeholders externos.

\section{REFERÊNCIAS}

BAMPI, A. C.; DIEL, J. O. O modelo multicampi de universidade e suas relações com a sociedade. In: XIII Coloquio de Gestión Universitaria en Américas. Disponível em: https://repositorio.ufsc.br/bitstream/handle/123456789/114920/2013281. Acesso em 01/11/2015.

BARDIN, L. Análise de conteúdo. São Paulo: Edições 70. 2011. 
BENEKE, J. H. Marketing the institution to prospective students - a review of brand management in higher education. International Journal of Business and Management, 6(1), 29-44. 2011.

BOWEN, W.G.; SHAPIRO, H. T. Universities and their leadership. Princeton University Press (pp. 33-37). 1998,

BRYSON, J. M. What to do when stakeholders matter: stakeholder identification and analysis techniques. Public Management Review 6 (1) p.21-53. 2004.

CHAPLEO, C.; SIMMS, C. Stakeholder analysis in higher education. Perspectives: Policy and Practice in Higher Education, 14(1), 12-20. 2010.

CLARKSON, M. A stakeholder framework for analyzing and evaluating corporate social performance. Academy of Management Review, 20(1): 92-117. 1995.

DONALDSON, T.; PRESTON, L. The stakeholder theory of the corporation: concepts, evidence and implications. Academy of Management Review, 20(1), 65-91. 1995.

DUDERSTADT, J. Fire, ready, aim: university-decision making during an era of rapid change. In: The Glion Colloquium II, La Jolla, California. 2000.

FREEMAN, R. E. Strategic Management: A Stakeholder Approach. Cambridge: Cambridge University Press.1984.

FROOMAN, J. Stakeholders influence strategies. Academy of Management Review, 24(2), 191-205. 1999.

GOODPASTOR K. Business ethics and stakeholder analysis. Business Ethics Quarterly, 1: 53-71. 1991.

GUPTA, M.; SINGH, P. B. Marketing \& branding higher education: issues and challenges. Review of Business Research, 10(1), 46-53. 2010. 
JOHNSON, G.; SCHOLES, K.; WHITTINGTON, R. Exploring corporate strategy: text \& cases (Vol.8). Harlow: Pearson Education. 2008.

JONGBLOED, B.; ENDERS, J.; SALERNO, C. Higher education and its communities: interconnections, interdependencies and research agenda. Higher Education, 56, 303-324. 2008.

JORGE, S. A. V.; OLIVEIRA, J. F.; FERREIRA, S. O papel social das universidades federais frente a política de desenvolvimento regional: os casos da UNIVASF, UFRB e UFERS. In: XXIV Seminário Nacional UNIVERSITAS/BR. Maringá-PR. Anais do XXIV Seminário Nacional UNIVERSITAS/BR. 2016. Disponível em: http://www.ppe.uem.br/xxivuniversitas/anais/trabalhos/e_6/6-013.pdf. Acesso em 12/12/2019.

KETTUNEN, J. The stakeholder map in higher education, Society, Education and Psychology, Vol. 78, 34-38. 2014.

KOTECHA, P. Branding, mergers, and the future of South African higher education. South African Universities Vice-Chancellors Association, Pretoria. 2003.

LOURENÇO, R. T.; MANO, M.). Os Stakeholders e as Instituições de Ensino Superior. In: 4º Conferencia FORGES (pp. 1-16). Luanda e Lubango, Angola. 2014. Disponível em: https://pdfs.semanticscholar.org/0f0d/0189e8315babd2675006e765d0308d46788a.p df. Acesso em: 9/12/2019.

MAINARDES, E. W, ALVES, H.; RAPOSO, M. Identifying Stakeholders in a Portuguese university: A case study. Revista de Educación, 362, 429-457. 2013.

MAINARDES, E. W.; ALVES, H.; RAPOSO, M. An exploratory research on the stakeholders of a university. Journal of Management and Strategy, 1 (1), 76. 2010. 
MATLAY, H. Entrepreneurship education in the U.K.: a critical analysis of stakeholder involvement and expectations. Journal of small business and enterprise development, 16(2), 355-368. 2009.

MITCHELL, R.; AGLE, B.; WOOD, D. Toward a theory of stakeholder identification and salience: defining the principle of who and what really counts. Academy of Management Review, 22(4), 853-858. 1997.

ROWLEY, T. Moving beyond dyadic ties: a network theory of stakeholder influences. Academy of Management Review, 22(4), 887-910. 1997.

VOLPI, M. T. A universidade e sua responsabilidade social. Porto Alegre: EDIPUCRS, 1996.

YIN R. K. Case Study Research: Design and Methods, 3rd edition. Sage Publications, Thousand Oaks, CA. 2003.

Enviado: Março, 2020.

Aprovado: Junho, 2020. 